\title{
Implementation of the Lean Manufacturing in Local Small and Medium Sized Enterprises
}

\author{
Oualid kherbach, Marian Liviu Mocan and Cristian Dumitrache \\ Faculty of management in production and transportation, Department of management, Politehnica \\ University of Timisoara, Romania \\ Correspondence should be addressed to: Oualid kherbach; oualidkherbach@gmail.com
}

Received date: 21 September 2015; Accepted date: 1 May 2016; Published date: 18 September 2017

Academic Editor: Josef Dvorak

Copyright (C) 2017. Oualid kherbach, Marian Liviu Mocan and Cristian Dumitrache . Distributed under Creative Commons CC-BY 4.0

\begin{abstract}
Manufacturing organizations have adopted the concept of lean manufacturing in order to develop the quality of their products and decrease their wastes. This is done by guarantee that products are evaluate or assessed at each and every stage hence costs are decreased. The objective of this study was to investigate the lean manufacturing apply in small manufacturers companies in Romania and to observe the level of accepting of the concept. The implementation and benefits of the lean manufacturing refer to level of education of employees.This research is a cross sectional study which is conducted as an email survey. Accordingly, 25 companies have been surveyed to investigate the tendency for small manufacturers entreprises in Romania to analyse the existence of lean methods for the application in this type of organization and difficulties in the implementation stage and to identify the critical success factors. The results of this preliminary study should illustrate the existing hidden potential in small and medium sized enterprises and it is found that $87 \%$ of factories in this survey indicated that the employees need lean training. Awareness of the existence of such needs can help management and training providers to establish appropriate preparation strategies for the successful implementation of a lean program in SMEs
\end{abstract}

Keywords: Survey, Lean Manufacturing, Small Manufacturers

\section{Introduction}

The global market has dramatically changed during the past years. Therefore, products with low quality, long lead time, and limited diversity are no longer adequate among customers. Client's demands are rising by time and traditional production systems cannot meet this new level of demand. Then, applying new production methods in order to produce high quality product, in small amount of time, with low cost becomes important for existence in the present competitive global market (Mirzaei, 2011).

Cite this Article as: Oualid kherbach, Marian Liviu Mocan and Cristian Dumitrache (2017), "Implementation of the Lean Manufacturing in Local Small and Medium Sized Enterprises ", Journal of

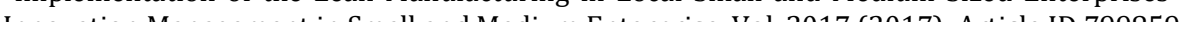


The economic improves utilized in Central and East European countries have to highlight the position of SMEs because they are able to produce an essential digit of new jobs, to encourage competition for better similar firms, to create a flexible and different industrial environment, to stimulate improvement, to develop industrial relations and to give a better working situation for employees within of a general economy. Derived from these features, the SME sector was considered a key aspect for assuring the reorganization of the old national economies and preserving economic dynamism (Negrusa, 2011).

SMEs play a central and a vital part in the global economy. Current observed studies show SMEs are important in terms of their overall share of GDP that SME's participate to over $55 \%$ of GDP and over $65 \%$ of total appointment in high-income countries. SME's and easy enterprises, description for over $60 \%$ of GDP and more $70 \%$ of total employment in low-income countries, although they contribute more $95 \%$ of total placement also about $70 \%$ of GDP in middle-income countries.

In the European Union countries, SMEs make up $99.8 \%$ of all enterprises; in the EU28 there are some 20 million small businesses, they appoint approximately 95 million people, provide almost $65 \%$ of total employees in the private sector. The main contribution is productivity growth and exports (Canan et al., 2008).

Lean manufacturing has been created by large companies and used by them to raise production output and performance from the beginning of the 1990s. Since then, many companies around the globe, generally large ones, have been enjoying features resulted from the achievement of lean production in their organizations. Though, even though the possible competitive benefits caused by lean production (Matt \& Rauch, 2013).

SMEs have not applied lean as widespread as large companies. A small number of investigators have been studying the implementation of lean in SMEs and attempted to understand whether lean production suits this particular type of company. Womack et al. (1990) showed that lean production is appropriate in every organization. Billesbach (1991) and Womack et al. (1990) showed that some of the related factors such as culture, country of origin, and employee's agreement can also influence lean implementation.

Most of the evidence from the studies and research done in Romania that related to the lean implementation is actual implementation and applied research that intended to develop some features of a process with the lean tools. However, there is no clear evidence of the level of success and problems/barriers of the implementation. The problems that might cause the company to stumble may root from the perceptions of management and employees toward the LM (Chaisorn and Lila, 2011); Shah and Ward, 2003; Marinescu and Toma, 2006; Panizzolo,1998).

The aim of this study was to investigate the present situations of Lean manufacturing, terms of attitude, implementation, problems/barriers, effectiveness and level of understanding of the concepts in the industry in Romania. In addition to discovery perceptions that could be used as guidelines for setting company strategies for successful lean implementation program.

\section{Review of Literature}

In the literature review of Lean manufacturing, small companies are very different from large ones in a lot of areas, such as management method, production developments, obtainable capital, purchasing practices, inventory systems, and negotiating power (Lee, 2007).The significance of small manufacturer (SME) to take part in lean implementation is support with large manufacturer which perform new management system that is lean manufacturing, as to develop their interpretation (Lila, 2012). The implementation of Lean Production in large 
companies, considering the size classes we can observe that Lean Manufacturing concepts are essentially possible by large companies (Matt and Rauch, 2013). An enforcement of Lean Production concepts in small and medium sized enterprises with less than ten persons employed wouldn't make sense. On the other hand, for several small enterprises between 10 and 49 employees the implementation of Lean Manufacturing could be one main step to raise the productivity and to be more competitive on the market (Matt and Rauch 2013).

In addition, they indicated that mainly small manufacturing firms are attractive for applying Lean manufacturing because of assured necessary features of Lean manufacturing such as its simplicity and no important capital savings required. Actually, many small and medium sized firms all over the world have already implemented Lean manufacturing, different studies propose the application of Lean manufacturing to small firms by classifying more attractive situations in small firms than in large firms (White and Achanga et al 2006; Womack et al 1990; Womack et al. 1996). SMEs are yet not positive of the charge of its performance and the tangibility of the results and advantages they may reach. Most of these companies fright that applying lean manufacturing is expensive and time consuming (Achanga et al., 2005). Evaluated to larger firms, small firms have smaller number of resources and often less entrance to capital. Some Lean manufacturing advantages may be moderately more significant for small manufacturing firms, can benefit by improving competitiveness through earlier originality and production, increasing flexibility and reducing costs.

Small firms have the benefit to be more flexible than large companies. A long time ago they make a decision to insert Lean Production methods, small business managers can frequently bring change more quickly in small firms than is commonly possible in larger firms because they have less system of government, have shorter contact lines and are less bound by custom. The easy nature of smaller businesses and management of owner/managers can make the performance of Lean production programs as a result comfortable in small firms than in large ones (Hyland and Kennedy, 2004).

\section{Lean Production and SMEs}

\section{lean manufacturing}

Lean manufacturing is rooted in the Toyota production who enhanced market share by improving their operations, most principally on the shop floor, but in design and growth as well (Parry et al., 2010). Lean manufacturing has all the time more individual employed as a possible solution for many industries. Organizations are motivated to be lean so as to keep on globally competitive. As of the lens of lean change, organizations aim to understand "leanness" in their operations. (Subashini and kumar, 2013)

Lean Manufacturing is especially known by investigators and practitioners; Womack and Jones, (1990) reported that the adoption of lean approach will "change almost everything in every industrychoices for consumers, the character of work, and fortune of industry by combining the benefits of abilities and huge production". The Lean manufacturing approach contains several practices, which want to get enhanced efficiency, quality and awareness to customers (Rose et al., 2014). Lean production is an integrated socio-technical system whose main objective is to eliminate waste by concurrently reducing or minimizing supplier, customer, and internal variability (Shah and Ward, 2007). Lewis (2000) described Lean production as follows:

"Lean production is a reduced level of input resources in the system for a given level of output. This is completed by removing waste (muda) from the system. This is mainly waste in the form of resources (raw material, WIP etc) that are transformed in manufacturing but in addition contains transforming resources such as people, facilities, process technology etc." 
As mentioned before the major purpose of lean production is to eliminate this waste (muda). Waste (muda) is classified in two types regarding their avoidance opportunity. The primary kindof encompasses the activities which produce no value though it is impossible to remove them by means of the present available technologies and production resources. The second kind contains activities which create no value and can be removed from the system immediately (Womack and Jones, 2003).

\section{Manufacturing SMEs: Attributes Applicable for the Improvement of LSS- Based Lean Manufacturing}

The literature points out that SMEs significant difference starting large organizations, SMEs having comparatively familiar structures and culture, small management teams with a high degree of cross-functional contacts. Snider et al. (2009), Gélinas and Bigras (2004), and Ates and Bititci (2011) have focused on implementation in an SME-context, but they do not focus particularly on the implementation of quality improvement practices. The SME-characteristics presented in Table 1 are understood to be applicable for the management of change processes. Implementing a continuous enhancement program can be observed as a change process.

\section{Implementation of Lean in SMEs}

Womack et al. (1990) concluded that the lean manufacturing is applicable in all industries across the world. Richard et al. (1999) supported this and stated that improvement practices such as lean and JIT are useful for both small and large companies despite the size factor. Karlsson and Åhlström (1996) reported that mainly the lean practices can be implemented by SMEs, although they are developed based on large companies. Richard et al. (1999) came to the same conclusion in their investigation and even realized that practices such as creating multifunctional teams, quality circles, total productive maintenance are easier to apply in SMEs. However, they also realized that practices like JIT purchasing are more difficult for SMES to implement compared to large companies. In addition, their contextual factor and the substantial size of the firm influence the achievement of lean production (Shah and Ward, 2003).

SMEs, as a result of their small size, have some barriers which made them slightly dissimilar in evaluation with large enterprises concerning useful implementation of lean. Not all the JIT practices are suitable to be implemented in SMEs (Im and Lee 1989; Ahmed et al. 1991; Richard, et al. 1999). In the following some of the factors which make SMEs different and some of the implementation success factors for SMEs which have been mentioned in literature.

Table 1: SME-features important for implementing change

\begin{tabular}{|c|c|}
\hline $\mathbf{N r}$ & SME-features important for implementing change \\
\hline 1 & $\begin{array}{l}\text { There is a lack of human and financial resources (Ates, Snider). SMEs cannot afford } \\
\text { extensive training. (Snider) }\end{array}$ \\
\hline 2 & A firefighting approach is used to solve day-to-day problems. (Ates) \\
\hline$\overline{3}$ & The culture of the organization is characterized as a command and control culture. (Ates) \\
\hline 4 & $\begin{array}{l}\text { The owner-manager has a need for self-government, independence and power, shared with a } \\
\text { low partiality to delegate and consult. (Gélinas, Mintzberg) }\end{array}$ \\
\hline 5 & $\begin{array}{l}\text { Strategies are instinctive and opportunistic and the process of strategic planning is } \\
\text { incremental combined with a moderately short planning horizon. (Gélinas, Ates, Snider) }\end{array}$ \\
\hline 6 & The main organizing mechanism is direct administration. (Mintzberg) \\
\hline 7 & Owner-manager is in direct contact with operations. (Gélinas) \\
\hline 8 & $\begin{array}{l}\text { The structure and culture are easy; a small management group operates with an efficient } \\
\text { decision making process. (Gélinas, Ates, Snider) }\end{array}$ \\
\hline 9 & The organization is flexible (Gélinas) and organic (Burns \& Stalker, Mintzberg ) \\
\hline
\end{tabular}

Oualid kherbach, Marian Liviu Mocan and Cristian Dumitrache (2017), Journal of Innovation Management in Small and Medium Enterprise, DOI: 10.5171/2017. 799859 


\section{Research Methodology}

The aims of this explore were to explore the positions of lean concepts in the Romanian industry related manufacturing located in industrial property in Timisoara region by surveying the perception of their employees in terms of the following;

- $\quad$ Attitude of employees

- $\quad$ Application LM

- $\quad$ Problems/barriers

- Usefulness

- Level of accepting. These items were involved into a set of questions in the questionnaires.

The research follows 5 steps. They are; explanation of population and sample, design and testing of questionnaires, data collection, analysis and conclusions.

\section{Definition of population and sample}

A questionnaire was developed to collect data for this study. In order to achieve the objectives of the study, the Romanian manufacturing SMEs firms were chosen as the population. The database was achieved from the 2015 SMEs Corp Timisoara directories.This list of the manufacturing firms consists of materials of construction, automotive, metal, plastic, rubber and other industry components. The manufacturing firms concerned in this study were ranged from medium to small companies, with more than 10 employees. According to SME Corp, medium companies are those with full time workers between 51-150 while large companies have full time workers over 151 . The decision made in this study is derived from the studies done by Lila (2012). From their studies it is shown that small manufacturing firms are less likely to apply LM concepts due to positive limitations and barriers. The workers involved in the survey were those from managing directors, manufacturing and/or production managers and executives, and also quality managers and executives. The main inquiry of the study was to find out the attitude employees and level of understanding of manufacturers whose production processes related to SMEs manufacturing, located in Timisoara.

\section{Design and testing of questionnaires}

The questionnaire consisted of 3 parts; (1) the background information of the organisation (year of establishment, ownership, personal information, and quality system certification); (2) the lean manufacturing implementation (lean practices implementation, employees toward, attitude, advantages and barriers); and (3) consists of multiple choice questions to assess the level of the lean understanding the respondent information . The objects of lean manufacturing achievement section were adapted from Shah and Ward (2007) and Panizzolo (1998). The questions were arranged in five-points Likert scale to evaluate the level of implementation explained by each of the items. The scale was ranged from 1 to 5 where $1=$ no implementation, $2=$ little implementation, $3=$ some implementation, $4=$ extensive implementation, and $5=$ complete implementation. Achieving Part 3 questionnaires would be interpreted according to the range of $0-3,4-6$ and 7-10 as low, moderate and high levels of understanding of the lean concepts. The main concern of the design in this survey implement was to keep it short and focused in order to get a sufficient response rate. The process of improving the questionnaire also included a pilot survey. This direct survey was used to revise and eliminate the number of variables. Experts from academics and industries were also reviewed. In the questionnaire format, the observations and feedback were analysed and a few minor adjustment were made particularly. Common of the feedback from the experts gave helpful remarks and confirmed that the questionnaire was suitable for the collection of data. While no new items were added for the data collection part, many items were revised or adapted. The questionnaire was then ready for data collection. In the case of reliability and validity, were checked with 30 . Cronbach's alpha was decided to be 0.70 , although it may be as low as 0.60 in

Oualid kherbach, Marian Liviu Mocan and Cristian Dumitrache (2017), Journal of Innovation Management in Small and Medium Enterprise, DOI: 10.5171/2017. 799859 
investigative research (Field ,2006) for the internal uniformity of the questionnaires.

\section{Data collection}

Considering the purpose of the exploratory study, the convenience sampling method was used to collect data. The questionnaire was sent to industry companies located in Timisoara, Romania. A two step sampling was applied in choosing sample firms, stratification and random samplings. Four representatives from each chosen factory were requisite to fill the questionnaires that were sent via E-mails and via electronic. Skilled operations managers to top management staffs working in industry companies were the target respondents or involve in immediate how a firm operates its production systems.

\section{Results and Discussion}

Collecting data was used from 25 industry companies; responses from participants were collected, coded, and entered into a Microsoft Excel spreadsheet (Microsoft 2010). The data were coded according to the tracking number, the date received, definite, and open-ended answers. 100 respondents were lastly retrieved, 26 each from the management team, engineer or supervising team and operating teams. Result form part I of the survey is as shown in Table (1).

The first parts to be studied were the common background of the respondents and the firms included. The general background of the respondents such as education and the job position and years of employment in the company are presented in Table (2). Results showed that $72 \%$ of the respondents hold bachelor degree, $47 \%$ are workers in production management team, and $66 \%$ of the workers have 5-9 years of working experience.

The factors studied were the types of produce and firm period. Most of the respondent firms manufacture metal components for automotive industries (44.3\%). Popular of the companies involved in this study are categorised as intermediate (48\%) and $42 \%$ are old companies

The old companies defined in this study are those which were established more than 20 years ago. By evaluation, the intermediate companies are those which have been established between 11 to 20 years. New companies are defined as those which were established less than 10 years ago. The percentage of new companies was only $12 \%$ (Table 3). Unfortunately, as indicated in the survey that about $73 \%$ and $68 \%$ of employees who are involved with the production management and operations management hold bachelor degree or lower and have less than 5 years in that particular company, respectively. Consequently, it is found that $84 \%$ of factories in this survey indicate that their workers necessitate lean training. Then, the lean manufacturing is an acceptable philosophy for production management of the related industries located in Timisoara and Arad. On the other hand, more attention and effort to solve problems. The management should recognize the importance of the meaning to overcome these confrontations for the successful implementation of lean manufacturing system in their firms. In addition, training for engineering, supervising and operating teams are required for the success of the lean implementation. This finding has a suggestion for the firms as it gives a mean to help them to identify the factors that hamper or delay the implementation process. The respondents who have an education level higher than bachelor degree and more than 5 years of working experience and work at intermediate companies 10-20 years have better understanding of the lean concepts than others, respectively. 
Table 2: General background of the respondents

\begin{tabular}{|l|l|l|}
\hline Education & Count & Percentage \\
\hline High school & 9 & $9 \%$ \\
\hline bachelor degree & 72 & $72 \%$ \\
\hline bachelor degree & 19 & $19 \%$ \\
\hline Position in the company & & \\
\hline Production Management & 47 & $47 \%$ \\
\hline Engineering and supervising & 19 & $19 \%$ \\
\hline Other & 32 & $32 \%$ \\
\hline Years of employment & & \\
\hline$<5$ years & 13 & $13 \%$ \\
\hline $5-9$ years & 66 & $66 \%$ \\
\hline$>10$ years & 22 & $22 \%$ \\
\hline
\end{tabular}

The mean and standard deviation (SD) of perceptions of respondents about position toward the lean concepts, achievement, problem/barriers and efficiency are presented in Table 4.

Table 3: General background of the companies

\begin{tabular}{|l|l|l|}
\hline Types of product produced & Count & Percentage \\
\hline $\begin{array}{l}\text { Gender } \\
\text { Male }\end{array}$ & & \\
Female & 47 & 47 \\
\cline { 2 - 3 } & 53 & 53 \\
\hline Plastic parts & 4 & $16 \%$ \\
\hline Metal parts & 11 & $44 \%$ \\
\hline Construction parts & 3 & $12 \%$ \\
\hline Electronic parts & 2 & $8 \%$ \\
\hline automotive & 5 & $20 \%$ \\
\hline Company age (year) & & \\
\hline New (<9 years & 3 & $12 \%$ \\
\hline Intermediate (10-20) & 12 & $48 \%$ \\
\hline Old (>20) & 10 & $40 \%$ \\
\hline
\end{tabular}

Results of the understanding of the lean concepts indicated that the attitude employees and effectiveness employees are at positive levels but only at the moderate levels of adequacy for action taken in real achievement and effort to explain problems of managements. Most of the respondents (68\%) expressed high level of understanding of the lean concepts (Table 5). 
Table 4: Mean and SD of perceptions from respondents

\begin{tabular}{|l|l|l|l|}
\hline Perception & mean & SD & Meaning \\
\hline Problem/barriers & 2.93 & 0.88 & Not significant \\
\hline Attitude employees & 3.87 & 0.65 & Significant \\
\hline Application LM & 2.82 & 0.86 & Not significant \\
\hline Efficiency employees & 3.84 & 0.59 & Significant \\
\hline
\end{tabular}

The level of accepting of the lean concepts was found to be at high level and depended on education and experience. It was promote indentified that respondents who have an education level higher than bachelor degree and more than 5 years of working experience and work at old company. In this study, those which were established more than 10 years ago have enhanced understanding of the lean concepts than other groups. The respondent firms indicate that their engineers and supervisors do not have adequate information about the LM and 87\% employees need Lean Manufacturing training.

\section{Table 5: Lean concepts understanding level}

\begin{tabular}{|l|l|l|}
\hline \multicolumn{1}{|c|}{ Level of understanding } & \multicolumn{1}{c|}{ Count } & Percentage \\
\hline High level & 68 & $68 \%$ \\
\hline moderate & 27 & $27 \%$ \\
\hline Low level & 5 & $5 \%$ \\
\hline
\end{tabular}

\section{Conclusions}

Lean manufacturing gives a new supervision approach for a lot of small and medium size manufacturers, particularly older companies arranged and managed under traditional push systems. The results of this survey indicate that the $48.2 \%$ from the lasting $41.8 \%$ of those that have not applied have planned to include the lean concepts in their processes. $87 \%$ of Romanian factories in this survey indicated that the employees need lean training. This training can help to establish appropriate preparation strategies for the successful performance of a lean program in Romanian SMEs.

\section{References}

1. Achanga, P., Shehab, E., Roy, R. and Nelder, G. (2006).'Critical success factors forlean implementation within SMEs. Journal of Manufacturing Technology Management, 17 (4), 460-471.
2. Ahmed, NU., Tun, EAC. and Montagno, RV. (1991), 'A comparative study of U.S. manufacturing firms at various stages of just-in- time implementation.International Journal of Production Research,29, 787802.

3. Ates, A and Bititci, US. (2011),'Change management process: A key enabler to building resilient SMEs,' International Journal Production Research 49 (18), 56015618.

4. Billesbach, T. (1991) 'A study of the implementation of just-in-time in the United States,' Production and inventory management journal, 32 (3), 1-4.

5. Canan, ŞC., Hidayet, K., Kiriş,Y., Türköz,P., M. and Kiriş,MH. (2008). 'Can SMEs in developing countries resist crisis? An analysis on Turkish and Albanian cases' First international conference on Balkans studies (ICBS), ISBN: 978-99956-681-3-6, 07-08 November 2009, Tirana, Albania, 208-234. 
6. Chaisorn, N. and Lila, B. (2011), 'A Design and Development of the Real Time Electronic Pull System' International Conference on Industrial Engineering and Engineering Management (IEEM), ISBN: 978-8329-3433-0, 6-9 December 2011, Convention Centre, Singapore.

7. Field, A. (2006). Discovering statistic using SPSS, 2nd Ed. Sage Publications, London

8. Gélinas, R and Bigras, Y. (2004),'The characteristics and features of SMEs: Favorable or unfavorable to logistics integration,' Journal of Small Business Management 42 (3), 263-278.

9. Hyland, P., Kennedy, J. and Robert,M. (2004). 'Company Size and the Adoption of Manufacturing Technology'.Journal of New Business Ideas and Trends, 2 (1), 66-74.

10.Im, JH and Lee, SM. (1989),'Implementation of just-in-time systems in U.S. manufacturing firms', International Journal of Operations and Production Management 9 (1), 5-14.

11.Karlsson, C and Ahlström, P. (1996).'The Difficult Path to Lean Product Development', Journal of product Innovation 13 (4), 283-295.

12.Lee, C Y. (2007) 'JIT Production by Small Manufacturing Firms in China: An Exploratory Study,' Journal of International Management Studies, 2 (1), 54-64.

13.Lewis, M A. (2000) 'Lean production and sustainable competitive advantage,' Internationaljournal of Operations \& Production Management, 20 (8), 959-978.

14.Lila, B. (2012), 'A Survey on Implementation of the Lean Manufacturing in Automotive Manufacturers in the Eastern Region of Thailand' Proceedings of the2nd International Conference on Industrial Technology and Management(ICITM), ISBN: 9810733313, 9789810733315, 1-2 September 2012, Phuket Island, Thailand, 43-48.
15.Marinescu, P. and Toma, GS. (2006), 'Implementing Lean Management in the Romanian Industry' Proceedings of the International Conference on Advanced Production Management Systems (ICAPMS), ISBN: 978-0-387-77248-6, 9-10 October 2006, Tokyo, Japan, 269-276.

16.Matt, DT. and Rauch, E. (2013), 'Implementation of Lean Production in small sized Enterprises' Proceedings of the 8th Conference on Intelligent Computation in Manufacturing Engineering (CIRP), ISBN: 18-20 July 2012, Ischia (Naples), Italy, 420425.

17.Mirzaei, P. (2011). lean production: introduction and implementation barriers with SMEs in Sweden, jönköping university, Sweden.

18. Negrusa, A. (2011) 'Implementation of Just-In-Time in Romanian Small Companies,' Supply Chain Management Journal, 2 (2), 31-35.

19.Panizzolo, R. (1998) 'Applying the Lessons Learned from 27 Lean Manufacturers. The Relevance of Relationships Management,' International Journal of Production Economics, 55(3), 223-240.

20.Richard, EW., John, N P. and Jeffrey, RW. (1999), 'A Survey of Implementations in Small and Large U.S. Manufacturers,' Management Science, 45 (1), 1-15.

21.Rose, ANM., Deros, B.M. and Rahman, MNA. (2014).'Critical Success Factors for Implementing Lean Manufacturing in Malaysian Automotive Industry,' Research Journal of Applied Sciences, Engineering and Technology, 8 (10), 1191-1200.

22.Shah, R and Ward, PT. (2003), 'Lean Manufacturing: Context, Practice Bundles and Performance,' Journal of Operations Management (21), 129-149.

23.Shah, R and Ward, PT. (2007), 'Defining and developing measures of lean production,' Journal of Operations Management 25 (4), 785-805. 
24.Snider, B., Silveira, GJCD.and Balakrishnan, J. (2009).'ERP implementation at SMEs: analysis of five Canadian cases,' International Journal of Operations and Production Management, 29 (1), 4-29.

25.Subashini, GS and kuma, SM. (2013), 'An investigation on adoption of lean production principles in kitchenware manufacturing industries,' Interdisciplinary journal of contemporary research in business, 4 (9), 271-279.

26.Womack, JP,.Jones, DT and Roos, D. (1990) The Machine that Changed the World, Ed. Harper Perennial, NY, USA.

27.Womack, J and Jones, DT. (2003) Lean Thinking: Banish Waste and Create Wealth for Your Corporation (2nd), Simon and Schuster, New York, USA. 